\title{
Symbolic action priming relies on intact neural transmission along the retino-geniculo-striate pathway
}

Citation for published version (APA):

Sack, A. T., van der Mark, S., Schuhmann, T., Schwarzbach, J., \& Goebel, R. (2009). Symbolic action priming relies on intact neural transmission along the retino-geniculo-striate pathway. Neuroimage, 44(1), 284-293. https://doi.org/10.1016/j.neuroimage.2008.07.030

Document status and date:

Published: 01/01/2009

DOI:

10.1016/j.neuroimage.2008.07.030

Document Version:

Publisher's PDF, also known as Version of record

Document license:

Taverne

Please check the document version of this publication:

- A submitted manuscript is the version of the article upon submission and before peer-review. There can be important differences between the submitted version and the official published version of record.

People interested in the research are advised to contact the author for the final version of the publication, or visit the DOI to the publisher's website.

- The final author version and the galley proof are versions of the publication after peer review.

- The final published version features the final layout of the paper including the volume, issue and page numbers.

Link to publication

\footnotetext{
General rights rights.

- You may freely distribute the URL identifying the publication in the public portal. please follow below link for the End User Agreement:

www.umlib.nl/taverne-license

Take down policy

If you believe that this document breaches copyright please contact us at:

repository@maastrichtuniversity.nl

providing details and we will investigate your claim.
}

Copyright and moral rights for the publications made accessible in the public portal are retained by the authors and/or other copyright owners and it is a condition of accessing publications that users recognise and abide by the legal requirements associated with these

- Users may download and print one copy of any publication from the public portal for the purpose of private study or research.

- You may not further distribute the material or use it for any profit-making activity or commercial gain

If the publication is distributed under the terms of Article $25 \mathrm{fa}$ of the Dutch Copyright Act, indicated by the "Taverne" license above, 


\title{
Symbolic action priming relies on intact neural transmission along the retino-geniculo-striate pathway
}

\author{
Alexander Thomas Sack ${ }^{\mathrm{a}, *}$, Sanne van der Mark ${ }^{\mathrm{b}}$, Teresa Schuhmann ${ }^{\text {a }}$, Jens Schwarzbach ${ }^{\mathrm{c}}$, Rainer Goebel ${ }^{\mathrm{a}}$ \\ a Department of Cognitive Neuroscience, Faculty of Psychology and Neuroscience, Maastricht University, P.O. Box 616, 6200 MD Maastricht, The Netherlands \\ b Magnetic Resonance Center, University Children's Hospital, Steinwiesstrasse 75, CH-8032 Zürich, Switzerland \\ c Center for Mind/Brain Sciences, Trento University, Via Tartarotti, 7, 38068 Rovereto (TN), Italy
}

\section{A R T I C L E I N F O}

\section{Article history:}

Received 1 June 2008

Revised 10 July 2008

Accepted 17 July 2008

Available online 25 July 2008

\begin{abstract}
A B S T R A C T
Recent psychophysics studies suggest that the behavioral impact of a visual stimulus and its conscious visual recognition underlie two functionally dissociated neuronal processes. Previous TMS studies have demonstrated that certain features of a visual stimulus can still be processed despite TMS-induced disruption of perception. Here, we tested whether symbolic action priming also remains intact despite TMSinduced masking of the prime. We applied single-pulse TMS over primary visual cortex at various temporal intervals from $20 \mathrm{~ms}$ to $120 \mathrm{~ms}$ during a supraliminal action priming paradigm. This TMS protocol enabled us to identify at what exact time point a TMS-induced activity disruption of primary visual cortex interferes with conscious visual perception of the prime versus (un)conscious behavioral priming of the visual target stimulus. We also introduced spatial uncertainty by presenting visual stimuli either above or below the fixation cross, while the TMS pulse was always targeting the prime presented below fixation. We revealed that TMS over primary visual cortex interferes with both conscious visual perception and symbolic behavioral priming in a temporarily and spatially specific manner, i.e., only when disrupting primary visual cortex at approximately the same temporal stage between 60 and $100 \mathrm{~ms}$ after prime onset, and only for those prime stimuli presented below fixation. These findings are in disagreement with the idea of subliminal action priming being mediated by neural pathways bypassing striate cortex, and rather suggest that symbolic action priming relies on an intact neural transmission along the retino-geniculo-striate pathway. The implications of our findings for previous reports of residual visual processing during striate TMS are discussed.
\end{abstract}

(c) 2008 Elsevier Inc. All rights reserved.

\section{Introduction}

Vision represents one of the most important and complex human sensory systems and much is known about how visual information is conveyed from the eyes to primary visual cortex and subsequent higher visual areas in the human brain (Desimone et al., 1984; Goodale and Milner, 1992; Milner, 1995; Milner and Goodale, 1995; Mishkin et al., 1983; Ungerleider and Mishkin, 1982). Visual information is transferred from the retina via the optic chiasm to the lateral geniculate nucleus (LGN), superior colliculus, and pulvinar. From these subcortical structures, the visual information is sent to primary visual cortex (V1) in the occipital lobe of the brain, after which the stream of visual information bifurcates into a ventral 'what' stream (via inferior temporal cortex) associated with object recognition, and a dorsal 'where' stream (via parietal cortex) associated with the spatial localization of the visual stimulus (Desimone et al., 1984; Goodale and Milner, 1992; Milner, 1995; Milner and Goodale, 1995; Mishkin et al., 1983; Ungerleider and Mishkin, 1982). However, the seemingly simple

\footnotetext{
* Corresponding author. Fax: +31 433884125.

E-mail address: a.sack@psychology.unimaas.nl (A.T. Sack).
}

question on how we become consciously aware of what we perceive is still controversially discussed (Crick and Koch, 1995; Lamme and Roelfsema, 2000; Lamme et al., 2000; Milner, 1995; Milner and Goodale, 1995; Tong, 2003).

An intriguing aspect of this debate is the fact that being aware of a visual stimulus is not a prerequisite for exerting a subsequent behavioral impact (Lamme and Roelfsema, 2000; Vorberg et al., 2003; Weiskrantz, 1996, 2004). Recent evidence from neuropsychological (Cowey and Stoerig, 1991; Lamme and Roelfsema, 2000; Lamme et al., 2000; Weiskrantz, 2004) and psychophysics studies (Eimer and Schlaghecken, 1998; Klotz and Neumann, 1999; Ogmen et al., 2003; Schacter and Buckner, 1998b; Vorberg et al., 2003) suggests that the conscious visual recognition of a visual stimulus and the behavioral impact of this stimulus may underlie two functionally dissociated neuronal processes (Lamme and Roelfsema, 2000; Vorberg et al., 2003; Weiskrantz, 1996, 2004). Thus, although the visual information may not reach the level of conscious awareness under certain circumstances, it may still be processed to affect subsequent behavior (Vorberg et al., 2003; Weiskrantz, 1996, 2004). Such a functional dissociation between conscious visual recognition and action priming has, e.g., been demonstrated in psychophysical 
visual masking and priming experiments (Vorberg et al., 2003). Vorberg et al. (2003) used meta contrast visual masking to investigate the question of how the priming potential of a visual stimulus is related to its phenomenal experience. The authors revealed the phenomenon of 'subliminal priming', which means that the priming function increases with prime-target asynchrony, despite perfect masking of the prime. The authors claim that this indicates a dissociation between the effects that 'masks' have on action and on conscious perception. They conclude that relevant stimulus features may be fully processed up to the level of motor control, while remaining unavailable for conscious report. Hence, although the visually masked prime stimuli were not consciously perceived, they still exerted a measurable and systematic impact on the reaction time to certain features of a sequentially presented visual target stimulus (Eimer and Schlaghecken, 1998; Klotz and Neumann, 1999; Ogmen et al., 2003; Schacter and Buckner, 1998b; Vorberg et al., 2003).

The proposed neural visual processing mechanisms underlying this observed functional dissociation between conscious perception and action priming are controversial. It has, for example, been suggested that priming without awareness may occur via different processing routes in different scenarios, thus that conscious perception and action priming are mediated by two distinct processing pathways, transferring the visual information along different neuronal streams (Goodale and Milner, 1992; Goodale et al., 1991; James et al., 2003; Milner and Goodale, 1995; Ungerleider and Mishkin, 1982). According to these models, subliminal action priming relies on a functioning geniculo-extrastriate (Stoerig and Cowey, 1989, 1992) or extrageniculate retinotectal (Boyer et al., 2005; Poppel et al., 1973; Rafal et al., 1990; Ro et al., 2004; Weiskrantz et al., 1974) visual pathway that bypasses V1, directly transferring neural activity from subcortical regions within the thalamus to higher visual and subsequent motor regions (e.g. Kaas and Huerta, 1988; Robinson and McClurkin, 1989). Similarly, the distinction between 'vision for perception' (ventral pathway) and 'vision for action' (dorsal pathway) (Milner and Goodale, 1998) predicts that after a lesion in primary visual cortex, an interruption in the stream of information towards the ventrally located extrastriate areas blocks visual awareness, whereas visual input is still able to reach the dorsally located parietal cortex through routes bypassing V1 (Desimone et al., 1984; Goodale and Milner, 1992; Milner, 1995; Milner and Goodale, 1995; Mishkin et al., 1983; Ungerleider and Mishkin, 1982).

Alternatively, it has also been suggested that subliminal action priming relies on an intact retino-geniculo-striate pathway, and that action priming without conscious awareness may in fact be mediated by preserved "islands" of cortex in V1 (Fendrich et al., 1992). In a similar vein, another account of subliminal priming that does not rely on the striate versus extrastriate dichotomy claims that the prime stimulus causes both, a fast transient and a slower sustained activity in the magnocellular and parvocellular pathways, respectively. Subsequently, the visual mask is displayed and causes similar activities with a delay identical to the prime-mask stimulus-onset-asynchrony (SOA). Due to the inter-channel connections, the transient activity of the mask (in the fast magnocellular-channel) may suppress the sustained activity of the prime (in the slower parvocellular-channel), which leads to decreased prime visibility, i.e. meta contrast masking. Nevertheless, the transient activity produced by the prime, which determines the ability of the subject to generate a fast motor response to the prime, stays unaffected (Breitmeyer and Ogmen, 2000; Breitmeyer et al., 2004; Ogmen et al., 2003; Purushothaman et al., 2000).

An elegant and most direct methodological approach of testing these various accounts of subliminal priming on a neuronal level and to thereby directly address the question whether striate or non-striate routes are needed for this kind of priming, is to use event-related transcranial magnetic stimulation (TMS) in order to experimentally disrupt local brain activity within striate cortex. Several previous TMS studies have already successfully demonstrated that conscious visual perception can be impaired in healthy participants when TMS is applied over primary visual cortex (V1) during visual recognition tasks (Amassian et al., 1989; Amassian et al., 1993, 1998; Beckers and Homberg, 1991; Corthout et al., 2000; Corthout et al., 1999a; Corthout et al., 1999b; Epstein and Zangaladze, 1996; Kamitani and Shimojo, 1999; Kammer et al., 2005a; Kammer et al., 2005b; Kammer et al., 2003; Kastner et al., 1998; Masur et al., 1993; Miller et al., 1996; Overgaard et al., 2004). In the current study, we utilized the high temporal resolution of TMS in order to disentangle the behavioral impact, i.e. action priming, from the subjective awareness, i.e. conscious perception, aspect of visual processing. We applied singlepulse TMS (spTMS) over primary visual cortex during the behaviorally controlled execution of a supraliminal action priming paradigm. We planned to identify at what exact time point a TMS-induced activity disruption of primary visual cortex interferes with conscious recognition of the prime and/or with its behavioral priming effect on a subsequent visual target. If action priming was to be mediated by the geniculo-extrastriate or extrageniculate retinotectal visual pathway, TMS-induced disruptions of V1 activity should exclusively interfere with conscious perception of the prime but not with its behavioral priming function. In contrast, in case action priming was to rely on an intact retino-geniculo-striate pathway, disrupting V1 activity with TMS should affect both, conscious perception of the prime and behavioral priming of the visual target. If, moreover, the dissociation between action priming versus conscious perception was to be mediated by a fast transient versus a slower sustained activity in the magnocellular and parvocellular pathways, disrupting V1 activity with TMS should affect conscious perception of the prime and behavioral priming of the visual target at two distinct functional time points (Paulus et al., 1999). Stimuli consisted of left and right visual arrows presented in quick succession. In the prime recognition task, participants were required to determine whether the first arrowshaped stimulus (prime) pointed to the left or right. This task determined the degree to which the prime stimulus reached conscious awareness. In the target priming task, participants were required to indicate the orientation of the second visual arrow stimulus (target) as quickly as possible. This task determined the response priming effect (Vorberg et al., 2003) as defined by the difference in reaction times when the target followed a congruent prime (arrow-shaped prime stimulus pointing in the same direction as the target), as compared to an incongruent prime (arrow pointing in the opposite direction). Despite the similarity of this paradigm to the combined meta contrast visual masking and action priming design adopted by Vorberg et al. (2003), we purposely decided to use prime and target parameters which prevented visual backward masking of the prime. Hence, in contrast to Vorberg et al. (2003), we did not use a visual masking task but rather employed a supraliminal priming task during which TMS acted as a "mask" for the prime stimulus. TMS was applied over primary visual cortex at various temporal intervals ranging from $20 \mathrm{~ms}$ to $120 \mathrm{~ms}$ following the presentation onset of the prime stimulus. This TMS protocol enabled us to identify and systematically compare the chronometry of functionally relevant primary visual cortex activity for the conscious visual recognition of the prime versus the response priming effect on the visual target.

\section{Methods}

\section{Overall study design}

The current study consists of two empirical parts: a psychophysics and a transcranial magnetic stimulation (TMS) experiment. The purpose of the preceding psychophysics session was to empirically determine the optimal prime-target stimulus-onset-asynchrony (SOA) in order to ensure i) reliable conscious perception of both visual stimuli (prime and target) and ii) strong behavioral priming of 
the target stimulus. In this sense, our paradigm was designed as a supraliminal priming task. An empirical calibration of such optimal psychophysical parameters was needed for the subsequent TMS experiment during which TMS acted as a "mask" for the prime stimulus, and which was specifically designed to disentangle the time courses of functionally relevant visual cortex activity for conscious visual perception versus behavioral priming. Please note that while the absence of a visual masking effect in our study is in contrast to the paradigm described by Vorberg et al. (2003), it is a prerequisite for employing disruptive TMS, for interpreting its effects and for comparison across studies.

\section{Methods}

\section{Participants}

Ten healthy volunteers were recruited from an academic environment (age range 19-27 years, 6 males). After the psychophysics session, seven participants (age range 19-25 years, 6 males) agreed to further participate in the subsequent TMS study. All participants were right handed and had no history of neurological or psychiatric disorder. Participants were informed about TMS and received a questionnaire to control for potential health risks and contraindications. None of the participants had any pervious experience with TMS vision studies. They gave their informed consent after being introduced to the procedure. The study was approved by the local medical ethical committee and conducted in accordance with the Declaration of Helsinki.

\section{Stimuli}

Visual stimuli consisted of two sequentially presented arrows pointing either to the left or to the right. The first arrow represented the prime stimulus and consisted of a completely black filled-in arrow subtending a visual angle of $2.8^{\circ} \times 1.1^{\circ}$. The second arrow represented the target stimulus and consisted of a white filled-in arrow subtending a visual angle of $5.5^{\circ} \times 2.8^{\circ}$ (see Fig. 1 for details). The inner contours of the target stimulus did not fall onto the outer contours of the prime in order to prevent visual masking (Francis, 1997). Both stimuli were presented in fast succession with four randomly varying stimulus-

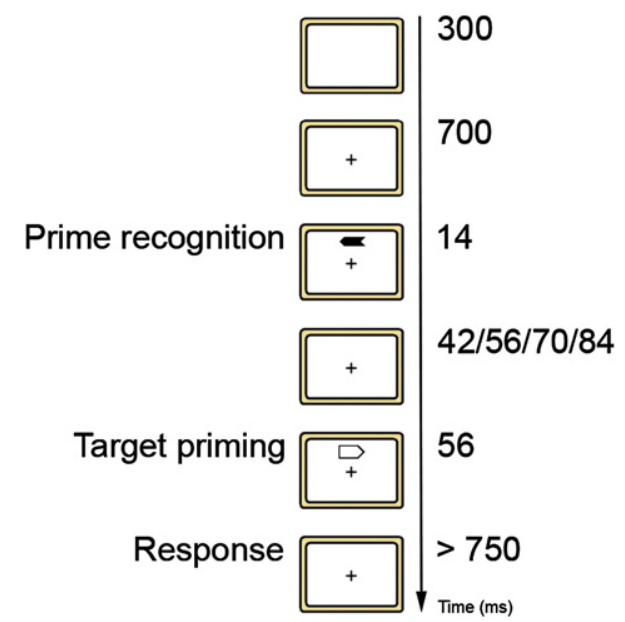

Fig. 1. Prime recognition and target priming task. Visual stimuli consisted of two sequentially presented arrows pointing either to the left or to the right. Prime (duration $=14 \mathrm{~ms}$ ) and target (duration $=56 \mathrm{~ms}$ ) stimuli were presented in fast succession with four randomly varying stimulus-onset-asynchronies (SOA: $42 \mathrm{~ms}$ $56 \mathrm{~ms}, 70 \mathrm{~ms}$, and $84 \mathrm{~ms}$ ), and could be either congruent (pointing in same direction) or incongruent (pointing in opposite directions). On a trial-by-trial basis, we introduced spatial uncertainty by presenting both stimuli either above or below the fixation cross in a randomized order. The prime recognition task required participants to respond to the orientation of the prime. In the target priming task, participants were required to respond as quickly and as accurately as possible to the orientation of the target stimulus. onset-asynchronies (SOA: $42 \mathrm{~ms}, 56 \mathrm{~ms}, 70 \mathrm{~ms}$, and $84 \mathrm{~ms}$ ). The prime was presented for 14, the target for 56 ms. Primes and targets were presented parafoveally at an angular distance of $3.4^{\circ}$ (for primes) or $4.4^{\circ}$ (for targets) from the fixation cross, either above or below the fixation cross. Prime and target were always presented at the same spatial location within the visual field and could be either congruent (both pointing in the same direction) or incongruent (pointing in opposite directions). On a trial-by-trial basis, we introduced spatial uncertainty by presenting both stimuli either above or below the fixation cross in a randomized order (Fig. 1). All visual stimuli were presented as black line drawings on a white background on a 21 inch CRT monitor at a refresh rate of 70-Hz. Viewing distance was $47 \mathrm{~cm}$. Visual stimuli were controlled using Presentation 9.30 (Neurobehavioral Systems Inc., Albany, USA) in Windows XP.

\section{Paradigm}

The paradigm consisted of two types of tasks: target priming and prime recognition. In the target priming task, participants were required to respond as quickly and as accurately as possible to the orientation of the target stimulus. This task was designed to reveal the prime-target congruency effect, which was determined by subtracting the reaction time (RT) of congruent trials from those of incongruent trials. The prime recognition task required participants to respond to the orientation of the prime. Relative accuracy was used as a measure to determine the prime visibility (Fig. 1). The psychophysics session always preceded the TMS experiments. For the TMS studies, target priming task and prime recognition task were performed in separate experimental sessions. The order of both task sessions was counterbalanced across participants.

\section{Psychophysics procedure}

Participants were seated in a comfortable chair with their head positioned in a chin rest. After receiving test instructions, participants underwent two training blocks of 96 trials each in which they familiarized themselves with the task and optimized their response speed and accuracy. Visual feedback was provided after each trial (correct, incorrect, and missed) and summary feedback was given after each block (number of correct responses, percent-correct and mean RT). During the real experiment, feedback was presented on error trials only.

In the target priming task, each trial started with a blank screen (300 ms), followed by a central fixation cross $(700 \mathrm{~ms})$, and the prime stimulus which was randomly presented either below or above the fixation cross. After a randomly selected SOA of either $42,56,70$, or $84 \mathrm{~ms}$, the target stimulus appeared at the same spatial location as the prime. At the end of each trial, another fixation screen appeared with a maximal duration of 750 ms. Participants had to react as quickly and accurately as possible to the direction of the target stimulus by pressing one out of two buttons of a response box. The index finger of the right hand indicated that the arrow pointed to the right, while the index finger of the left hand signaled a left arrow direction. Primetarget SOA, prime and target orientation (left or right) and stimulus position (above or below fixation) were randomly selected and balanced in each block (Fig. 1).

In the prime recognition task, prime visibility was assessed by asking participants to respond quickly and accurately to the orientation of the prime stimulus. The prime stimuli were the same as in the target priming task. However, instead of a target arrow stimulus, a neutral square-shaped stimulus $\left(4.14^{\circ} \times 2.8^{\circ}\right)$ was used. This was done to avoid conceptual masking because the target arrow orientation may have biased prime recognition reports. Moreover, participants were asked to respond only after a delay of $600 \mathrm{~ms}$ in order to prevent indirect priming effects on recognition (Vorberg et al., 2003). To achieve this, a red-colored fixation cross directly presented after the 
neutral stimulus turned green after a delay of $600 \mathrm{~ms}$, thereby indicating that participants should now respond to the orientation of the prime. Their reaction format was the same as in the target priming task.

Both tasks consisted of 192 trials split into 3 blocks of 64 trials. Inter-block intermission was at least $20 \mathrm{~s}$. Half of the trials were incongruent trials.

\section{Psychophysics statistical analyses}

Prior to statistical analyses, data were trimmed by removing the upper and lower $5 \%$ of the data. Only behavioral measures of correctly performed trials, determined per participant and condition, were included in the analysis. The data were averaged across participants. The correction for multiple comparisons was done following the Fisher's LSD procedure. Target priming effects were analyzed across a range of SOAs within a 2-factorial repeated-measures ANOVA with prime-target SOA (4 levels: $42,56,70$, or $84 \mathrm{~ms}$ ), and prime-target congruency (2 levels: congruent versus incongruent prime) as the two within-subject factors. Prime recognition was analyzed within a oneway repeated-measures ANOVA with prime-target SOA as a withinsubject factor.

\section{TMS procedure}

For the TMS experiments, single pulses of TMS were applied over the primary visual cortex at various time intervals following the presentation of the prime stimulus. A fixed prime-target SOA of $84 \mathrm{~ms}$ was used, chosen based on the results of the preceding psychophysics session, where an SOA of $84 \mathrm{~ms}$ showed the strongest target priming effect (see Psychophysics experiment).

The TMS experiment was divided into four experimental sessions in order to i) determine and validate the exact TMS target stimulation site above primary visual cortex in each participant, ii) apply TMS over visual cortex during the performance of the target priming task, iii) apply TMS over visual cortex during the performance of the prime recognition task, and iv) conduct a behavioral baseline session without TMS.

\section{TMS localization}

The exact TMS coil position was determined by applying TMS over the visual cortex and inducing phosphenes at various spatial locations within the visual field. Starting at a maximum stimulator output intensity of 50\%, the center of the coil was positioned $2 \mathrm{~cm}$ above the inion. The coil was then moved laterally and single pulses of TMS were applied until a clear phosphene was perceived in the contralateral visual field (Fig. 2). Phosphene perception had to fulfill the following three criteria in every single participant (Kammer et al., 2005a; Kammer et al., 2005b) a) dependence on the stimulated hemisphere, i.e. perception in the left visual field with stimulation at the right occipital pole and vice versa (Meyer et al., 1991); b) visibility with eyes both open and closed (Kammer and Beck, 2002); c) dependence on gaze direction (Meyer et al., 1991). On the basis of the retinotopic organization of TMS-induced phosphenes, the entire procedure aimed at positioning the TMS coil in such a way that the evoked phosphenes exactly overlaid the spatial location within the visual field where the prime stimuli presented below the fixation cross would appear. This location was identified by having the participant report when the phosphenes covered a continuously presented image of a prime stimulus positioned below fixation, while the participant focused on the fixation cross. This procedure ensured that the exact TMS target site above visual cortex corresponded to the retinotopic representation of the prime stimulus position below fixation (Thut et al., 2003b). This TMS target position was recorded and digitized using frameless stereotaxy (BrainVoyager TMS Neuronavigator (BrainInnovation,

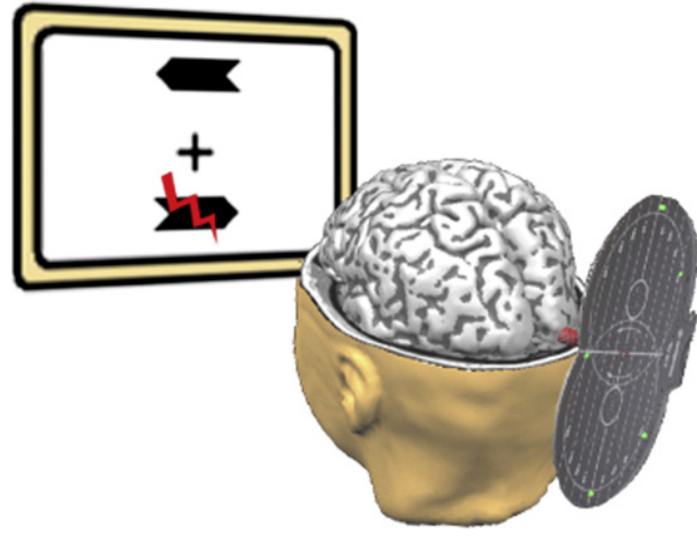

Fig. 2. TMS target stimulation site. The exact TMS coil position was determined by applying TMS over the visual cortex and inducing phosphenes at various spatial locations within the visual field. On the basis of the retinotopic organization of TMSinduced phosphenes, we ensured that the exact TMS target site above visual cortex corresponded to the retinotopic representation of the prime stimulus position below fixation. This TMS target position was recorded and digitized using frameless stereotaxy (BrainVoyager TMS Neuronavigator (BrainInnovation, Maastricht, The Netherlands), for a reliable and accurate re-positioning of the TMS coil across the subsequent TMS sessions.

Maastricht, The Netherlands), for a reliable and accurate re-positioning of the TMS coil across the subsequent TMS sessions. In addition, an MRI-derived head model was used to co-register and cross reference the functionally defined target stimulation site with the respective underlying individual anatomical brain region (Fig. 2).

\section{TMS protocol}

Biphasic TMS pulses were applied over the pre-determined target site within the visual cortex using a Medtronic MagPro R 30 stimulator (Medtronic Functional Diagnostics A/S, Skovlunde, Denmark; maximum stimulator output, $1.9 \mathrm{~T}$ ) and a figure-of-eight TMS coil (MC$\mathrm{B} 70$, the inner and outer radii of the two coil loops are 1.2 and $5.4 \mathrm{~cm}$, respectively). The figure-of-eight coil was fixed on a custom-made coil holder and placed tangentially on the skull. The handle was oriented parallel to the horizontal plane pointing towards the occiput. Singlepulse TMS was applied at $80 \%$ of maximum stimulator output. To avoid computer monitor artifacts and to provide accurate timing, the TMS pulses were applied in the vertical refresh period of the cathoderay-tube (CRT) monitor. TMS pulses were administered over visual cortex at six different time points following prime stimulus onset, testing a temporal range between 20 and $120 \mathrm{~ms}$ in steps of $20 \mathrm{~ms}$. Please note that at a TMS SOA of $100 \mathrm{~ms}$ and $120 \mathrm{~ms}$ after prime onset, TMS pulses are in fact also administered after visual target stimulus onset with an SOA of $16 \mathrm{~ms}$ and $36 \mathrm{~ms}$, respectively. Stimulus position (above or below fixation), prime and target orientation (left or right arrow) and TMS time window (20-120 ms in steps of $20 \mathrm{~ms}$ ) were randomly selected and balanced in each block.

\section{TMS statistical analyses}

Data trimming, outlier analysis, and data transformation procedures were identical to the psychophysics session. For both tasks reaction time and accuracy (\%hits) data were averaged across participants as the depended variables for all subsequent data analyses. The correction for multiple comparisons was done following the Fisher's LSD procedure. The effect of TMS on prime recognition was analyzed within a 2-way repeated-measures ANOVA with TMS time window (6 levels: $20-120 \mathrm{~ms}$ in steps of $20 \mathrm{~ms}$ ) and stimulus position ( 2 levels: above versus below fixation) as the two withinsubject factors. Post hoc simple contrast analyses were performed to determine at which exact time windows TMS affected prime 
A

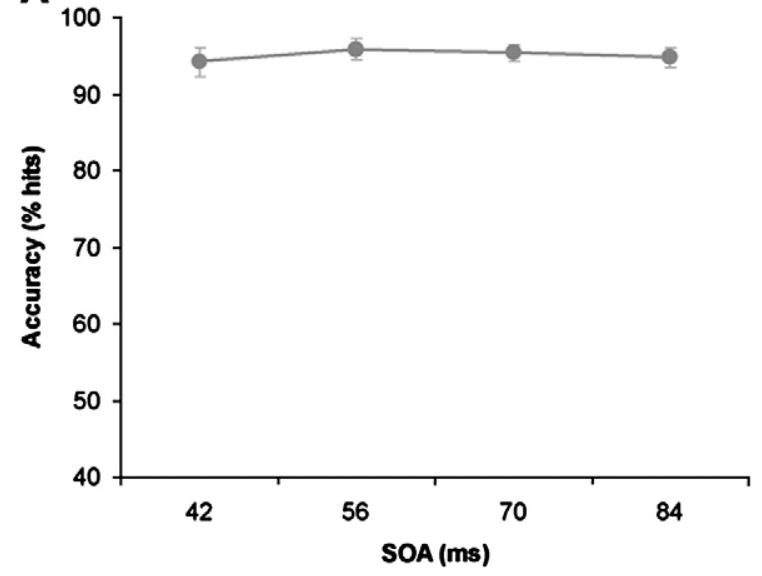

B
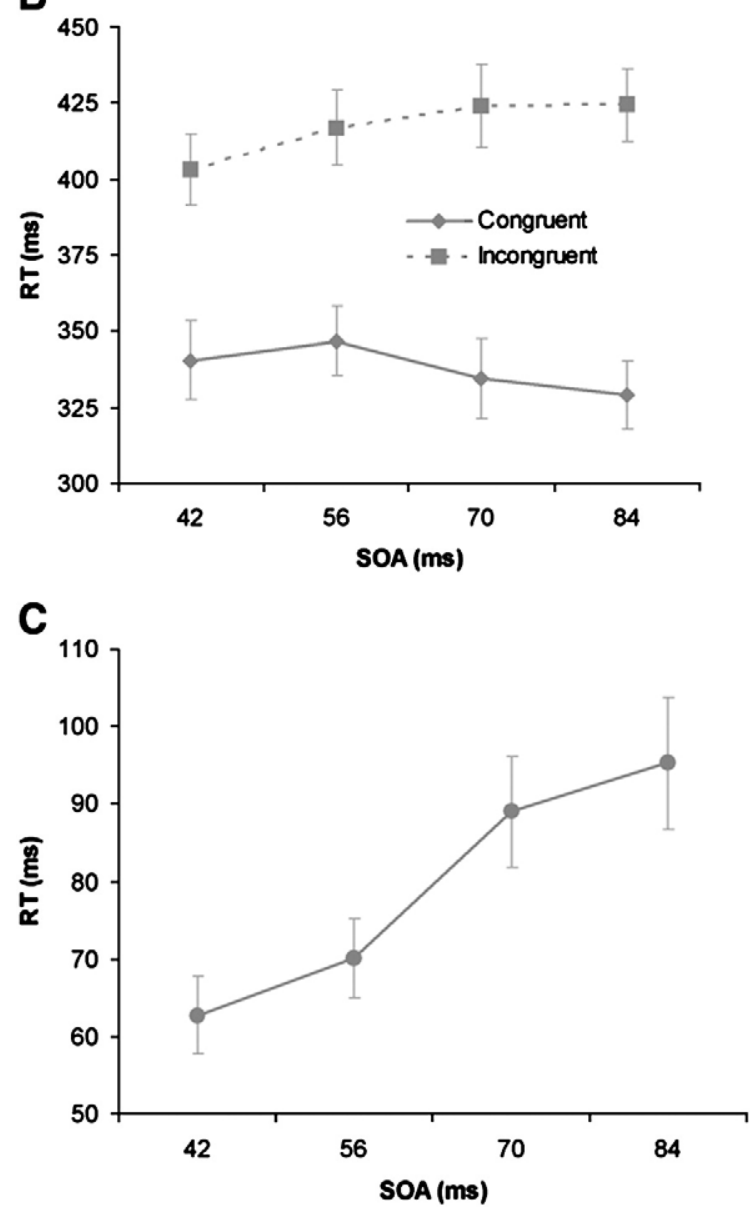

Fig. 3. Results psychophysics studies. (A) Prime visibility as a function of prime-target SOA measured by the mean \% accuracy scores of correctly recognized primes as a function of prime-target SOA. (B) Mean reaction time needed to respond to the visual target in case of a congruent (solid line) or incongruent (dotted line) prime stimulus. (C) Priming function measured by subtracting the RT on incongruent trials from the RT on congruent trials as a function of prime-target SOA.

recognition. In the target priming experiment, the effect of TMS on priming was analyzed by conducting a 3-way repeated-measures ANOVA with congruency (2 levels: congruent versus incongruent trials), TMS time window (6 levels: $20-120 \mathrm{~ms}$ in steps of $20 \mathrm{~ms}$ ) and stimulus position (2 levels: above versus below fixation) as the three within-subject factors. Post hoc simple contrast analyses were performed to identify at which exact time windows TMS affected target priming.

\section{Results}

Psychophysics experiment

Prime recognition task

In the prime recognition task, participants were required to determine whether the first arrow-shaped stimulus (prime) pointed to the left or right. This task determined the degree to which the prime stimulus reached conscious awareness. Prime visibility was assessed by computing a one-way repeated-measures ANOVA for the factor prime-target SOA on the mean percent-correct data (left and right primes collapsed). We did not reveal an effect of SOA on prime recognition $(F(3,27)=.493, p=.690)$, indicating that the accuracy function does not differ significantly between different prime-target SOA's. The percent of correctly recognized primes varied between 95 and 98 percent across all SOA's, indicating that prime recognition was well above chance level at all SOA's (Fig. 3A).

\section{Target priming task}

In the target priming task, participants were required to indicate the orientation of the second visual arrow stimulus (target) as quickly as possible. This task determined the response priming effect as defined by the difference in reaction times when the target followed a congruent prime as compared to an incongruent prime. The analyses of the RT data in response to the orientation of the target stimulus revealed a clear prime-target congruency effect with congruent primes leading to faster responses to the orientation of the target as

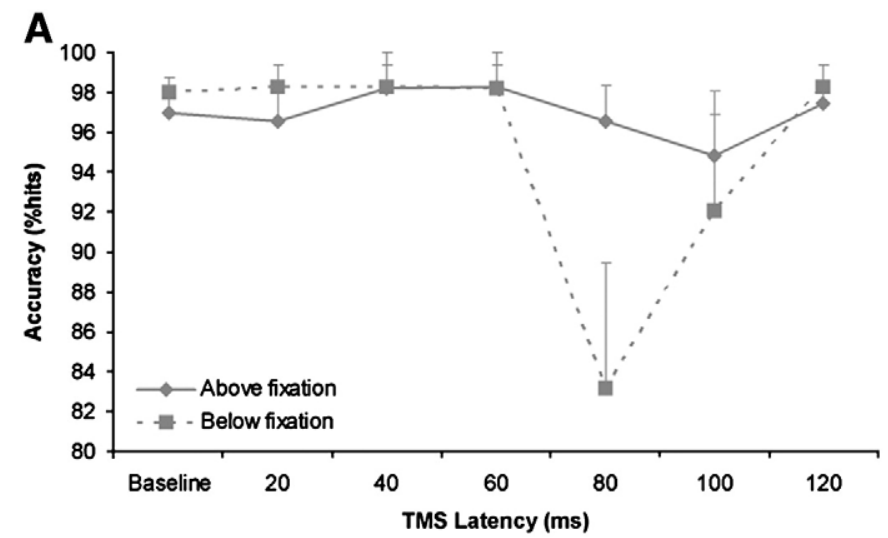

B

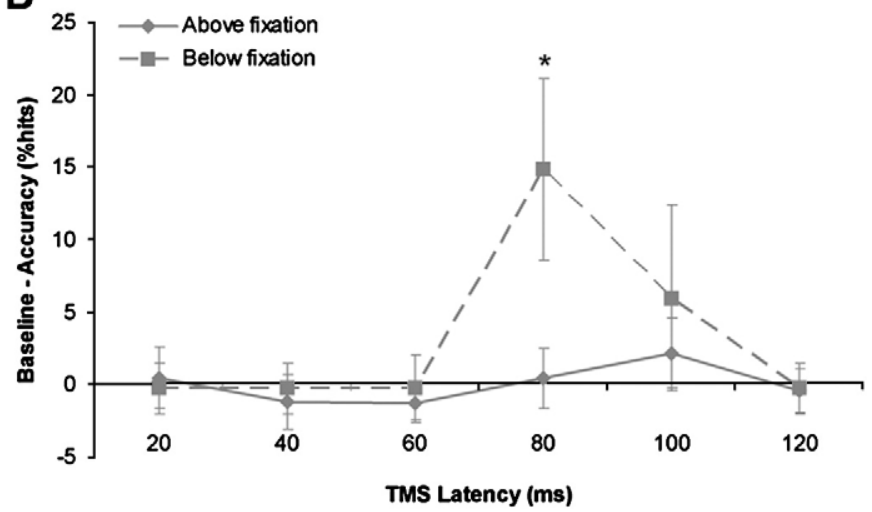

Fig. 4. Results of TMS during prime recognition. (A) Effects of V1-TMS on prime recognition task measured by the mean \% accuracy scores of correctly recognized primes as a function of prime-TMS SOA. Results are shown separately for stimuli presented above (solid line) and below (dotted line) fixation. (B) Effects of V1-TMS on prime recognition for prime stimuli presented measured by subtracting for each TMS time window the mean \% accuracy scores from baseline. Results are shown separately for stimuli presented above (solid line) and below (dotted line) fixation. Asterisks indicate significant TMS time windows. 
compared to incongruent primes (Fig. 3B). Statistically, the 2-way repeated-measures ANOVA revealed a main effect of congruency and SOA $(F(1,9)=209.04, p<.001$ and $F(3,27)=7.62, p=.001$, respectively). Moreover, a significant congruency $\times \mathrm{SOA}$ interaction $(F(3,27)=13.23$, $p<.001$ ) was found, indicating that the size of the congruency effect differed between SOA's. More concretely, the RT difference between congruent and incongruent trials increased linearly with increasing SOA, being largest at a prime-target SOA of $84 \mathrm{~ms}$ (Fig. 3C).

Based on these results, we decided to use a fixed prime-target SOA of $84 \mathrm{~ms}$ for the subsequent TMS experiment.

\section{TMS experiments}

\section{Prime recognition task}

TMS-induced masking effects were analyzed by calculating prime visibility at every single time point of TMS application over visual cortex. Moreover, since the exact TMS target site of visual cortex was determined based on the retinotopic representation of the prime position presented below the fixation cross, TMS-induced masking effects were separately analyzed for trials with the prime presented below versus above fixation. A 2-factor repeated-measures ANOVA of the mean accuracy data revealed a significant main effect of TMS time window $(F(5,30)=4.164, p=0.005)$, and a significant interaction between TMS time window $\times$ stimulus position $(F(5,30)=3.333$, $p=0.016$ ). These results indicate that TMS over visual cortex interferes with conscious prime recognition at a specific moment in time, and that this time-specific TMS induced impairment in the visibility of the prime is significantly different for both stimulus positions (Figs. 4A, B). Post hoc simple contrast analyses revealed that stimuli below fixation showed one specific TMS time window ( $80 \mathrm{~ms}$ ) at which disruption of visual cortex had a significant impairing effect on the visibility of the prime $(t(6)=2.374, p=.05)$. At this time window of $80 \mathrm{~ms}$ after stimulus onset, prime recognition performance was decreased by 14\% (Fig. 4B). No such significant effect of TMS was found for trials with stimuli presented above fixation (Figs. 4A, B). Identical data analyses were performed on the reaction times acquired during the prime recognition task. A 2-way repeated-measures ANOVA did not reveal any significant results. The lack of any TMS time-window effects indicates that the time-specific drop in accuracy, as found for trials with a TMS latency of $80 \mathrm{~ms}$, cannot be attributed to a change in speed-accuracy trade-off.

In summary, this analysis demonstrated a TMS-induced suppression of prime visibility in both a temporarily and spatially specific manner, i.e., only when disrupting primary visual cortex activity at a time window of $80 \mathrm{~ms}$ after prime onset, and only for those prime stimuli presented below fixation.

\section{Target priming task}

TMS-induced changes in the priming function were analyzed by calculating the RT to the orientation of the target stimuli in dependence on prime-target congruency ( 2 levels: congruent versus incongruent), TMS time window (6 levels: $20-120 \mathrm{~ms}$ after prime onset), and spatial position of target stimuli (2 levels: above versus below fixation). A 3-factor within-subjects ANOVA revealed a significant main effect of congruency $(F(1,6)=27.582, p=0.002)$, indicating that on average RTs on congruent trials were faster than those on incongruent trials (Fig. 5A). Moreover, the analyses also revealed a significant interaction between congruency $\times$ TMS time

\section{A Below fixation}

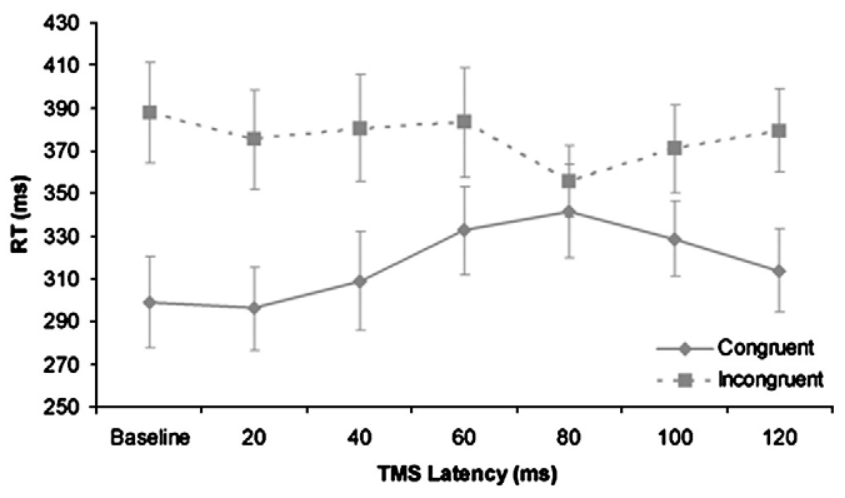

Above fixation

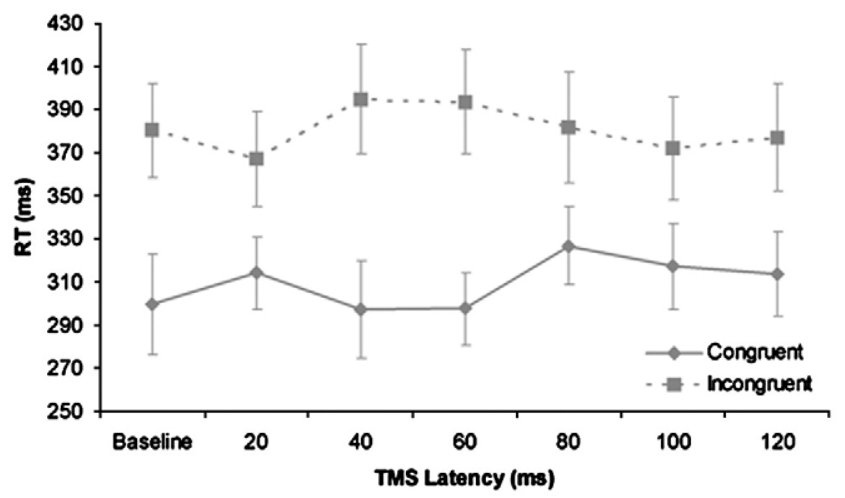

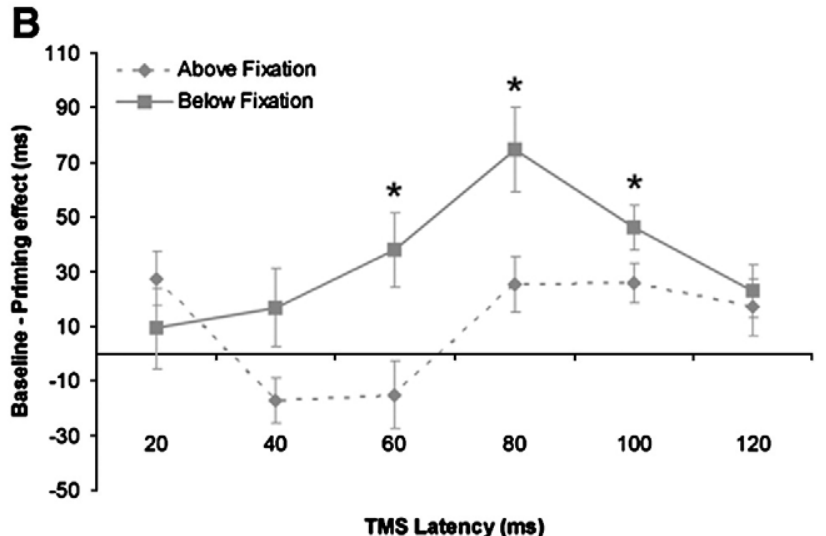

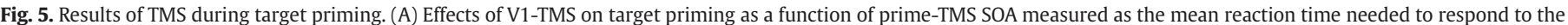

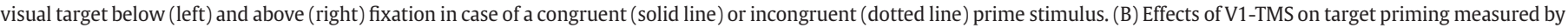

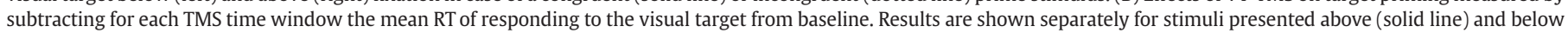
(dotted line) fixation. Asterisks indicate significant TMS time windows. 
window $(F(5,30)=5.792, p=0.001)$, and a significant interaction between congruency $\times$ stimulus position $(F(1,6)=21.05, p=0.004)$. While the former indicates that the size of the congruency effect significantly differed between the different TMS time windows (Fig. $5 \mathrm{~A}$ ), the latter further shows that the change in the congruency effect also depended on the spatial position of the target stimulus. Accordingly, we also revealed a significant second order interaction between congruency $\times$ TMS time window $\times$ stimulus position $(F(5,30)=$ $6.269, p<0.001$ ), indicating that the priming function is significantly affected by TMS in a time-specific manner (Fig. 5B), and that this timespecific effect of TMS in turn significantly differed between both spatial positions of the target stimuli. In accordance with this full factorial model, a 2-way within-subject ANOVA of the congruency effect (incongruent-congruent) revealed significant main effects of TMS time window $(F(5,30)=5.792, p=.001)$ and stimulus position $(F(1,6)=$ 21.05, $p=.004$ ) and), as well as a significant interaction between TMS time window $\times$ stimulus position $(F(5,30)=6.269, p<.001)$. The 3-way repeated-measures ANOVA on the accuracy data resulted in a significant main effect for the factor congruency $(F(1,6)=16.69$, $p=.06$ ), with the accuracy being higher for congruent as opposed to incongruent trials, as well as a significant first-order interaction between congruency $\times$ TMS time window $(F(5,30)=3.454, p=.014)$.

Post hoc simple contrast analyses revealed that this TMS-induced reduction of the priming effect occurred only for target stimuli presented below fixation, and only at the TMS time windows of $60 \mathrm{~ms}$ $(t(6)=2.790, p=.032), 80 \mathrm{~ms}(t(6)=4.812, p=.003)$, and $100 \mathrm{~ms}(t(6)=$ $5.661, p=.001$; see Fig. 5B). When analyzing separately for congruent versus incongruent trials, we revealed that TMS over visual cortex during congruent trials led to a significant slowdown of the response speed to the orientation of the target at TMS time windows 60,80 and $100 \mathrm{~ms}(t(6)=-2.711, p=.035$, mean $=-33.6 \mathrm{~ms} ; t(6)=-2.637, p=.039$, mean $=-42.6 \mathrm{~ms} ; t(6)=-3.561, p=.012$, mean $=-29.6 \mathrm{~ms}$, respectively). In contrast, during incongruent trials, TMS led to a significant improvement of the response speed to the orientation of the target at a TMS time window of $80 \mathrm{~ms}(t(6)=2.746, p=.033$, mean $=32 \mathrm{~ms})$. These results clearly demonstrate that a TMS-induced disruption of neural activity in visual cortex at a specific moment in time during visual processing annihilates the benefiting effect of a congruent prime while at the same time deteriorating the impairing effect of an incongruent prime on the response speed to a respective visual target stimulus (Fig. 5A).

In summary, these analyses demonstrated a TMS-induced reduction of the priming function in both a temporarily and spatially specific manner, i.e., only when disrupting primary visual cortex at a time window of $60-100 \mathrm{~ms}$ after prime onset, and only for those prime stimuli presented below fixation. Moreover, when charting and

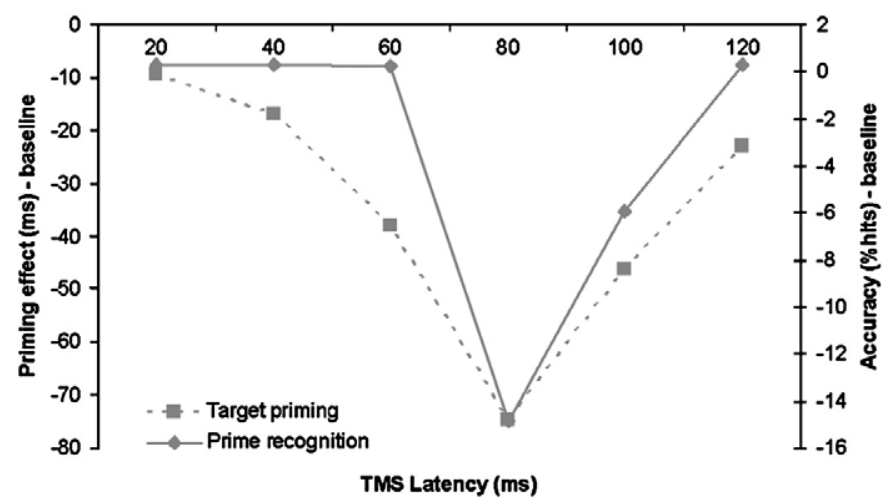

Fig. 6. Charting TMS effects on perception versus priming. Time-specific effects of TMS over primary visual cortex charted separately for the conscious recognition of the prime (solid line) versus its behavioral priming effect (dotted line). For each TMS time window, mean \% accuracy of prime recognition (right $y$-axis) as well as the mean RT needed to respond to the visual target (left $y$-axis) was subtracted from baseline. comparing both effects, the TMS-induced disruption of prime visibility and the TMS-induced impairment of the behavioral priming, as a function of TMS time window, we clearly reveal that TMS over primary visual cortex interferes with both processes at approximately the same temporal stage during visual information processing (Fig. 6).

\section{Discussion}

The purpose of the current study was to chart and systematically compare the time course of functionally critical neural activity in primary visual cortex for conscious prime recognition versus behavioral target priming in a combined meta contrast and action priming paradigm.

Our psychophysical results revealed a clear priming effect in which congruent primes lead to faster responses to the visual target as compared to incongruent primes. We also revealed that this congruency effect significantly increased with increasing stimulusonset-asynchronies between prime and target stimulus. This result is in accordance with the findings of Vorberg et al. (2003), who also showed an interaction between priming function and SOA in terms of a linearly increasing priming effect with increasing SOA.

In the subsequent TMS experiment, we revealed that TMS over visual cortex caused a disruption of conscious prime recognition only when applied at $80 \mathrm{~ms}$ after prime stimulus onset. This time-specific effect of TMS over visual cortex is in accordance with several previous TMS studies consistently revealing that occipital TMS causes a visual suppression effect at stimulus-TMS intervals between 80 and $100 \mathrm{~ms}$ (Amassian et al., 1989; Amassian et al., 1993, 1998; Corthout et al., 2000; Overgaard et al., 2004). Interestingly, our data also revealed that this temporarily specific effect of visual cortex TMS is spatially specific and even topographically organized. In our study, the exact TMS target site of visual cortex was determined based on the retinotopic representation of the prime stimuli presented below the fixation cross as opposed to the prime stimuli presented above the fixation cross. The interaction between TMS time window $\times$ stimulus position indicates that the time-specific TMS-induced impairment in prime recognition is different for trials with the prime presented below versus above the fixation cross. We could show that only stimuli below fixation were affected by a TMS pulse delivered over the stimulation site at $80 \mathrm{~ms}$ after prime onset, whereas no effect of TMS was found for trials with stimuli presented above fixation. These findings reveal that the time-specific effect of occipital TMS on visual recognition is also spatially specific on a behavioral level, and even topographically organized. This finding complements earlier studies showing that under certain circumstances the disruptive effects of TMS on functional brain activity are spatially specific (Thut et al., 2003a; Thut et al., 2003b) similar to what has already been shown in the context of TMS-induced visual phosphenes (Kammer et al., 2005a; Kammer et al., 2005b).

The analyses of the target priming experiment revealed a breakdown of the behavioral priming function at three different TMS time windows, namely at $60 \mathrm{~ms}, 80 \mathrm{~ms}$, and $100 \mathrm{~ms}$ following prime stimulus onset. Interestingly, and similar to the TMS-induced masking effects, we revealed that this time-specific TMS-induced decrease in behavioral priming was only found for those stimuli presented below the fixation cross. TMS over primary visual cortex does disrupt the behavioral priming effect in both a temporarily and spatially specific manner, i.e., only when applied at a time window between 60 and $100 \mathrm{~ms}$ after prime onset, and only for those prime stimuli presented below fixation. More specifically, our results revealed that, compared to baseline, applying TMS between 60 and 100 ms over primary visual cortex during congruent trials led to a significant slowdown of the response speed to the orientation of the target, whereas during incongruent trials, TMS led to a significant improvement of the response speed to the orientation of the target. These results thus clearly demonstrate that a TMS-induced disruption of neural activity 
in primary visual cortex at a specific moment in time annihilates the benefiting effect of a congruent prime while at the same time deteriorating the impairing effect of an incongruent prime on the response speed to a respective visual target stimulus. Alternatively, the revealed time-specific performance enhancement induced by TMS during incongruent prime-target trials may also represent a direct functional improvement as opposed to a mere deterioration of the impairing effect of the incongruent prime. Such specific functional improvements of TMS have been described by previous studies to occur also in the context of TMS-induced disruptive effects over the same stimulation site dependent on task and behavioral context (see e.g. (Grosbras and Paus, 2003; Romei et al., 2007; Silvanto et al., 2007; Walsh et al., 1998).

Although TMS significantly reduced both, prime recognition and target priming, it did not totally suppress these functions. This lack of complete priming suppression may theoretically indicate the existence of some residual neural processing capacity not relying on striate cortex. However, it is much more likely that the absence of complete priming suppression during TMS is rather due to the interference limits inherent to the online single-pulse TMS protocol (see e.g. also Sack et al. ( 2006)). In sum, our empirical findings thus suggest that primary visual cortex is functionally relevant for both, conscious prime recognition and behavioral target priming, at approximately the same temporal stage during visual information processing. This indicates that an intact retino-geniculo-striate pathway is needed for the visual prime stimulus to exert its behavioral priming effect.

Our results are thus in disagreement with the idea of subliminal priming being mediated by neural pathways bypassing striate cortex. In our experiment, the behavioral priming effect of a visual stimulus was clearly impaired after disrupting primary visual cortex, indicating that when the feed forward sweep of neural information processing along the retino-geniculo-striate pathway is terminated at the level of striate cortex, both conscious perception and action priming are disrupted. Importantly, due to the adoption of an almost identical symbolic action priming paradigm, a direct comparison between our TMS study and the psychophysics study by Vorberg et al. (2003) is justified and appropriate. When making such a comparison, we argue that our findings do not contradict the described psychophysical studies revealing an intact priming function despite perfect masking of the prime stimulus (Eimer and Schlaghecken, 1998; Klotz and Neumann, 1999; Ogmen et al., 2003; Schacter and Buckner, 1998a; Vorberg et al., 2003). Our results rather indicate that masking induced by a visual stimulus versus masking induced by TMS leads to different behavioral results both in terms of optimal prime-mask/TMS SOA, as well as in terms of a functional dissociation between perception and priming. It has been, e.g., suggested that the TMS-induced masking effects between 80 and $100 \mathrm{~ms}$ might represent a disruption of the feedback activity from extrastriate regions to V1 (Corthout et al., 2000) as opposed to the feed forward sweep from the LGN. Few studies have indeed reported two distinct TMS time periods, one at a delay of -10 to $10 \mathrm{~ms}$ and another at a delay of $100 \mathrm{~ms}$ after stimulus onset, at which visual cortex activity is essential for the perception of visually presented stimuli (Hotson et al., 1994). The very early effect of TMS was claimed to represent the arrival of the raw visual information in the occipital cortex, while the later represented the feed backward sweep. However, our data failed to reveal such an early effect of TMSinduced primary visual cortex disruptions on prime visibility. In contrast, we revealed that the earliest effect of TMS-induced primary visual cortex disruption on visual recognition occurs at approximately $80 \mathrm{~ms}$ after stimulus onset. Based on our findings, we thus argue that the time window between 60 and 100 ms represents the early feed forward sweep of visual information processing in primary visual cortex, a claim in accordance with several previous TMS studies using various visual recognition paradigms (Amassian et al., 1989; Amassian et al., 1993, 1998; Corthout et al., 2000; Overgaard et al., 2004).
Moreover, the time window between 80 and $100 \mathrm{~ms}$ has also been described in several electrophysiological studies (Di Russo et al., 2003; Luck et al., 1997) and has consistently been labeled as the first feed forward sweep of neuronal activity within primary visual cortex coming from the retino-geniculo-striate pathway. Hence, although neural activity in V1 following visual stimulation can already be recorded at $35 \mathrm{~ms}$ post stimuli (Lamme and Roelfsema, 2000), these ERP and TMS studies indicate that the critical large scale synchronized population-level neural activity rather occurs at a time range between 80 and $120 \mathrm{~ms}$. Importantly, however, and in contrast to the TMSinduced termination of the retino-geniculo-striate feed forward sweep in V1 as realized in our study, visual meta contrast backward masking of the prime does not interfere with this early feed forward sweep to be processed and transferred. The prime causes a fast and thus early activity in V1, which gets further processed to frontal and motor brain regions giving rise to its behavioral priming effect. Conscious visual recognition of the prime, however, only occurs when recurrent feedback activity from higher visual areas re-enters V1 in the shape of a feed backward sweep (Bullier, 2001; Fenske et al., 2006; Lamme and Roelfsema, 2000; Laycock et al., 2007; Tong, 2003). While this latter process is disrupted in visual meta contrast masking leading to impaired prime visibility, the behavioral priming effect remains unaffected leading to the observed functional dissociation between conscious prime recognition and behavioral priming as described in the above mentioned psychophysical combined meta contrast masking and behavioral priming studies. In other words, during these psychophysics studies, masking occurs when an initial display (prime) is replaced on the screen by a different configuration (mask) before the required processing iterations of recurrent feedback loops have taken place for the visual prime to be recognized. In our TMS study, however, we directly interfered with the early feed forward sweep but not with the later feedback projections during visual information processing, which resulted in a breakdown of the action priming function.

Our findings may seem to be in direct conflict to some previous TMS studies reporting evidence that certain features of V1 TMSmasked stimuli, such as orientation and color, can still be processed despite TMS-induced disruption of perception (Boyer et al., 2005; Christensen et al., 2008; Ro, 2008). Unlike our current findings, these studies suggest a functioning geniculo-extrastriate visual pathway that bypasses V1 to process these stimulus features also in the absence of conscious awareness (Boyer et al., 2005). A recent study also showed that during TMS-induced masking of visual stimuli, ongoing reaching movement in response to these stimuli can still be corrected (Christensen et al., 2008). In a similar vein, Ro (2008) showed that TMS can be used to gate visual input into the dorsal visual processing stream by disrupting primary visual cortex (V1) function. In this study, restricting geniculo-striate processing contributions to the dorsal stream did not impair reaching performance from unconscious visual events, suggesting a functionally intact unconscious projection to the dorsal pathway from the superior colliculus that bypasses V1. However, although these studies investigated which features of a visual stimulus can still be processed during TMS-induced masking, or whether the redundant target effect, i.e. faster responses when an additional target is simultaneously presented (Marzi et al., 1986; Miller, 1982; Ro, 2008) occurs despite TMS over V1, none of these studies tested the influence of disrupting geniculo-striate processing on sequential behavioral action priming. In contrast, our experiment required participants to respond to the orientation of a visual target stimulus following the TMS-masked prime stimulus. Our findings suggest that while certain features of a TMS-masked stimulus may still be unconsciously processed, their action priming potential on subsequently presented target stimuli may nonetheless be significantly decreased. In this context, it is also worth speculating whether behavioral priming by a symbolic prime stimulus, in our case an arrow pointing to the left or right, may rely on intact geniculo-striate 
processing, whereas other prime features exerting more, e.g. reflexivelike spatial cues, would have resulted in successful geniculo-extrastriate priming. Future studies are needed to test different prime stimulus types and longer time intervals between prime stimulus onset and TMS pulses over primary visual cortex, potentially disentangling the early feed forward versus late feed backward sweep of visual information processing, in order to further investigate the neural bases underlying the functional dissociation between conscious visual perception and behavioral priming along the retinogeniculo-striate pathway.

\section{Acknowledgments}

A.T.S. and T.S. were supported by a grant from the Netherlands Organization for Scientific Research (NWO; grant numbers 452-06003 and 400-04-215). We thank our medical supervisor Cees van Leeuwen, and our independent physician Martin van Boxtel. The authors also wish to thank Christianne Jacobs for assisting in the statistical analyses and figure preparation, and four anonymous reviewers for their helpful comments on an earlier version of this article.

\section{References}

Amassian, V.E., Cracco, R.Q., Maccabee, P.J., Cracco, J.B., Rudell, A., Eberle, L., 1989. Suppression of visual perception by magnetic coil stimulation of human occipital cortex. Electroencephalogr. Clin. Neurophysiol. 74, 458-462.

Amassian, V.E., Cracco, R.Q., Maccabee, P.J., Cracco, J.B., Rudell, A.P., Eberle, L., 1993. Unmasking human visual perception with the magnetic coil and its relationship to hemispheric asymmetry. Brain Res. 605, 312-316.

Amassian, V.E., Cracco, R.Q., Maccabee, P.J., Cracco, J.B., Rudell, A.P., Eberle, L., 1998. Transcranial magnetic stimulation in study of the visual pathway. J. Clin. Neurophysiol. 15, 288-304.

Beckers, G., Homberg, V., 1991. Impairment of visual perception and visual short term memory scanning by transcranial magnetic stimulation of occipital cortex. Exp. Brain Res. 87, 421-432.

Boyer, J.L., Harrison, S., Ro, T., 2005. Unconscious processing of orientation and color without primary visual cortex. Proc. Natl. Acad. Sci. U. S. A. 102, 16875-16879.

Breitmeyer, B.G., Ogmen, H., 2000. Recent models and findings in visual backward masking: a comparison, review, and update. Percept. Psychophys. 62, 1572-1595.

Breitmeyer, B.G., Ro, T., Ogmen, H., 2004. A comparison of masking by visual and transcranial magnetic stimulation: implications for the study of conscious and unconscious visual processing. Conscious Cog. 13, 829-843.

Bullier, J., 2001. Feedback connections and conscious vision. Trends Cogn. Sci. 5 369-370.

Christensen, M.S., Kristiansen, L., Rowe, J.B., Nielsen, J.B., 2008. Action-blindsight in healthy subjects after transcranial magnetic stimulation. Proc. Natl. Acad. Sci. U. S. A. 105, 1353-1357.

Corthout, E., Uttl, B., Walsh, V., Hallett, M., Cowey, A., 1999a. Timing of activity in early visual cortex as revealed by transcranial magnetic stimulation. Neuroreport 10 , 2631-2634.

Corthout, E., Uttl, B., Ziemann, U., Cowey, A., Hallett, M., 1999b. Two periods of processing in the (circum)striate visual cortex as revealed by transcranial magnetic stimulation. Neuropsychologia 37, 137-145.

Corthout, E., Uttl, B., Juan, C.H., Hallett, M., Cowey, A., 2000. Suppression of vision by transcranial magnetic stimulation: a third mechanism. Neuroreport 11, 2345-2349.

Cowey, A., Stoerig, P., 1991. The neurobiology of blindsight. Trends Neurosci. 14, 140-145.

Crick, F., Koch, C., 1995. Are we aware of neural activity in primary visual cortex? Nature $375,121-123$.

Desimone, R., Albright, T.D., Gross, C.G., Bruce, C., 1984. Stimulus-selective properties of inferior temporal neurons in the macaque. J. Neurosci. 4, 2051-2062.

Di Russo, F., Martinez, A., Hillyard, S.A., 2003. Source analysis of event-related cortical activity during visuo-spatial attention. Cereb. Cortex 13, 486-499.

Eimer, M., Schlaghecken, F., 1998. Effects of masked stimuli on motor activation: behavioral and electrophysiological evidence. J. Exp. Psychol. Hum. Percept. Perform 24, 1737-1747.

Epstein, C.M., Zangaladze, A., 1996. Magnetic coil suppression of extrafoveal visual perception using disappearance targets. J. Clin. Neurophysiol. 13, 242-246.

Fendrich, R., Wessinger, C.M., Gazzaniga, M.S., 1992. Residual vision in a scotoma: implications for blindsight. Science 258, 1489-1491.

Fenske, M.J., Aminoff, E., Gronau, N., Bar, M., 2006. Top-down facilitation of visual object recognition: object-based and context-based contributions. Prog. Brain Res. 155, $3-21$.

Francis, G., 1997. Cortical dynamics of lateral inhibition: metacontrast masking. Psychol. Rev. 104, 572-594.

Goodale, M.A., Milner, A.D., 1992. Separate visual pathways for perception and action. Trends Neurosci. 15, 20-25.
Goodale, M.A., Milner, A.D., Jakobson, L.S., Carey, D.P., 1991. A neurological dissociation between perceiving objects and grasping them. Nature 349, 154-156.

Grosbras, M.H., Paus, T., 2003. Transcranial magnetic stimulation of the human frontal eye field facilitates visual awareness. Eur. J. Neurosci. 18, 3121-3126.

Hotson, J., Braun, D., Herzberg, W., Boman, D., 1994. Transcranial magnetic stimulation of extrastriate cortex degrades human motion direction discrimination. Vision Res. 34, 2115-2123.

James, T.W., Culham, J., Humphrey, G.K., Milner, A.D., Goodale, M.A., 2003. Ventral occipital lesions impair object recognition but not object-directed grasping: an fMRI study. Brain 126, 2463-2475.

Kaas, J.H., Huerta, M.F., 1988. The Subcotical Visual System of Primates. Comparative Primate Biology: Neurosciences. Wiley-Liss, New York.

Kamitani, Y., Shimojo, S., 1999. Manifestation of scotomas created by transcranial magnetic stimulation of human visual cortex. Nat. Neurosci. 2, 767-771.

Kammer, T., Beck, S., 2002. Phosphene thresholds evoked by transcranial magnetic stimulation are insensitive to short-lasting variations in ambient light. Exp. Brain Res. 145, 407-410

Kammer, T., Scharnowski, F., Herzog, M.H., 2003. Combining backward masking and transcranial magnetic stimulation in human observers. Neurosci. Lett. 343,171-174.

Kammer, T., Puls, K., Erb, M., Grodd, W., 2005a. Transcranial magnetic stimulation in the visual system. II. Characterization of induced phosphenes and scotomas. Exp. Brain Res. 160, 129-140.

Kammer, T., Puls, K., Strasburger, H., Hill, N.J., Wichmann, F.A., 2005b. Transcranial magnetic stimulation in the visual system. I. The psychophysics of visual suppression. Exp. Brain Res. 160, 118-128.

Kastner, S., Demmer, I., Ziemann, U., 1998. Transient visual field defects induced by transcranial magnetic stimulation over human occipital pole. Exp. Brain Res. 118, 19-26.

Klotz, W., Neumann, O., 1999. Motor activation without conscious discrimination in metacontrast masking. J. Exp. Psychol. Hum. Percept. Perform 25, 976-992.

Lamme, V.A., Roelfsema, P.R., 2000. The distinct modes of vision offered by feedforward and recurrent processing. Trends Neurosci. 23, 571-579.

Lamme, V.A., Super, H., Landman, R., Roelfsema, P.R., Spekreijse, H., 2000. The role of primary visual cortex (V1) in visual awareness. Vision Res. 40, 1507-1521.

Laycock, R., Crewther, D.P., Fitzgerald, P.B., Crewther, S.G., 2007. Evidence for fast signals and later processing in human V1/V2 and V5/MT+: a TMS study of motion perception. J. Neurophysiol. 98, 1253-1262.

Luck, S.J., Chelazzi, L., Hillyard, S.A., Desimone, R., 1997. Neural mechanisms of spatial selective attention in areas V1, V2, and V4 of macaque visual cortex. J. Neurophysiol. 77, 24-42.

Marzi, C.A., Tassinari, G., Aglioti, S., Lutzemberger, L., 1986. Spatial summation across the vertical meridian in hemianopics: a test of blindsight. Neuropsychologia 24 749-758.

Masur, H., Papke, K., Oberwittler, C., 1993. Suppression of visual perception by transcranial magnetic stimulation-experimental findings in healthy subjects and patients with optic neuritis. Electroencephalogr. Clin. Neurophysiol. 86, 259-267.

Meyer, B.U., Diehl, R., Steinmetz, H., Britton, T.C., Benecke, R., 1991. Magnetic stimuli applied over motor and visual cortex: influence of coil position and field polarity on motor responses, phosphenes, and eye movements. Electroencephalogr. Clin. Neurophysiol. Suppl. 43, 121-134.

Miller, J., 1982. Divided attention: evidence for coactivation with redundant signals Cognit. Psychol. 14, 247-279.

Miller, M.B., Fendrich, R., Eliassen, J.C., Demirel, S., Gazzaniga, M.S., 1996. Transcranial magnetic stimulation: delays in visual suppression due to luminance changes. Neuroreport 7, 1740-1744.

Milner, A.D., 1995. Cerebral correlates of visual awareness. Neuropsychologia 33,1117-1130

Milner, A.D., Goodale, M.A., 1995. The Visual Brain in Action. Oxford University Press, Oxford.

Milner, A.D., Goodale, M.A., 1998. The visual brain in action (precis). Psyche 4

Mishkin, M., Ungerleider, L.G., Macko, K.A., 1983. Object vision and spatial vision: two cortical pathways. Trends Neurosci. 6, 414-417.

Ogmen, H., Breitmeyer, B.G., Melvin, R., 2003. The what and where in visual masking. Vision Res. 43, 1337-1350.

Overgaard, M., Nielsen, J.F., Fuglsang-Frederiksen, A., 2004. A TMS study of the ventral projections from $\mathrm{V} 1$ with implications for the finding of neural correlates of consciousness. Brain Cog. 54, 58-64.

Paulus, W., Korinth, S., Wischer, S., Tergau, F., 1999. Differentiation of parvo- and magnocellular pathways by TMS at the occipital cortex. Electroencephalogr. Clin. Neurophysiol. Suppl. 51, 351-360.

Poppel, E., Held, R., Frost, D., 1973. Leter: residual visual function after brain wound involving the central visual pathways in man. Nature 243, 295-296.

Purushothaman, G., Ogmen, H., Bedell, H.E., 2000. Gamma-range oscillations in backward-masking functions and their putative neural correlates. Psychol. Rev. 107, 556-577.

Rafal, R., Smith, J., Krantz, J., Cohen, A., Brennan, C., 1990. Extrageniculate vision in hemianopic humans: saccade inhibition by signals in the blind field. Science 250 , $118-121$.

Ro, T., 2008. Unconscious vision in action. Neuropsychologia 46, 379-383.

Ro, T., Shelton, D., Lee, O.L., Chang, E., 2004. Extrageniculate mediation of unconscious vision in transcranial magnetic stimulation-induced blindsight. Proc. Natl. Acad. Sci. U. S. A. 101, 9933-9935.

Robinson, D.L., McClurkin, J.W., 1989. The visual superior colliculus and pulvinar. Rev Oculomot. Res. 3, 337-360.

Romei, V., Murray, M.M., Merabet, L.B., Thut, G., 2007. Occipital transcranial magnetic stimulation has opposing effects on visual and auditory stimulus detection: implications for multisensory interactions. J. Neurosci. 27, 11465-11472. 
Sack, A.T., Kohler, A., Linden, D.E., Goebel, R., Muckli, L., 2006. The temporal characteristics of motion processing in hMT/V5+: combining fMRI and neuronavigated TMS. Neuroimage 29, 1326-1335.

Schacter, D.L., Buckner, R.L., 1998a. On the relations among priming, conscious recollection, and intentional retrieval: evidence from neuroimaging research. Neurobiol. Learn Mem. 70, 284-303.

Schacter, D.L., Buckner, R.L., 1998b. Priming and the brain. Neuron 20, 185-195.

Silvanto, J., Muggleton, N.G., Cowey, A. Walsh, V 2007. Neural adaptation reveals statedependent effects of transcranial magnetic stimulation. Eur. J. Neurosci. 25, 1874-1881.

Stoerig, P., Cowey, A., 1989. Wavelength sensitivity in blindsight. Nature 342, 916-918 Stoerig, P., Cowey, A., 1992. Wavelength discrimination in blindsight. Brain 115 (Pt 2), 425-444.

Thut, G., Northoff, G., Ives, J.R., Kamitani, Y., Pfennig, A., Kampmann, F., Schomer, D.L., Pascual-Leone, A., 2003a. Effects of single-pulse transcranial magnetic stimulation (TMS) on functional brain activity: a combined event-related TMS and evoked potential study. Clin. Neurophysiol. 114, 2071-2080.

Thut, G., Theoret, H., Pfennig, A., Ives, J., Kampmann, F., Northoff, G., Pascual-Leone, A. 2003b. Differential effects of low-frequency rTMS at the occipital pole on visual- induced alpha desynchronization and visual-evoked potentials. Neuroimage 18 , 334-347.

Tong, F., 2003. Primary visual cortex and visual awareness. Nat. Rev. Neurosci. 4, 219-229.

Ungerleider, L.G., Mishkin, M., 1982. Two cortical visual systems. In: Engel, D.J., Goodale, M.A., Mansfield, R.J. (Eds.), Analysis of Visual Behavior. MIT Press, Cambridge, MA, pp. 549-586.

Vorberg, D., Mattler, U., Heinecke, A., Schmidt, T., Schwarzbach, J., 2003. Different time courses for visual perception and action priming. Proc. Natl. Acad. Sci. U. S. A. 100, 6275-6280.

Walsh, V., Ellison, A., Battelli, L., Cowey, A., 1998. Task-specific impairments and enhancements induced by magnetic stimulation of human visual area V5. Proc. Biol. Sci. 265, 537-543.

Weiskrantz, L., 1996. Blindsight revisited. Curr. Opin. Neurobiol. 6, 215-220.

Weiskrantz, L., 2004. Roots of blindsight. Prog. Brain Res. 144, 229-241.

Weiskrantz, L., Warrington, E.K., Sanders, M.D., Marshall, J., 1974. Visual capacity in the hemianopic field following a restricted occipital ablation. Brain 97, 709-728. 